\title{
La reelección en México: antecedentes y retos de la reforma electoral de 2013*
}

\section{Luis Carlos Ugalde** Gustavo Rivera Loret de Mola***}

\section{Sumario:}

I. El fundamento constitucional: el artículo 59

II. La reforma de 1933

III. El intento de contrarreforma de 1964

IV. El siglo XXI

V. La reforma constitucional de 2013

VI. La reelección en perspectiva comparada

VII. La reelección en el ámbito local de países federales

VIII. Conclusiones

IX. Bibliografía

* Este texto se basa en diversos artículos escritos y publicados por los autores y en el libro Vigilando al Ejecutivo: el papel del Congreso en la fiscalización del gasto público, 1970-1999, México, Miguel Ángel Porrúa-Cámara de Diputados, 2000.

** Fundador y director general de Integralia Consultores; ex consejero presidente del IFE.

*** Director ejecutivo de Integralia Pública, A. C. 
Esta revista forma parte del acervo de la Biblioteca Jurídica Virtual del Instituto de Investigaciones Jurídicas de la UNAM www.juridicas.unam. $\mathrm{mx}$

http://biblio.juridicas.unam.mx 
El 29 de abril de 1933 se promulgó la reforma constitucional que prohibió la reelección inmediata de legisladores, vigente por 80 años. Ese intermedio concluyó en febrero de 2014, cuando se promulgó una reforma constitucional que la permite como había sido el caso durante buena parte de la vida independiente de México. Ni Francisco I. Madero ni el Constituyente del 17 tuvieron en mente tal restricción. Sin embargo, miembros del Partido Nacional Revolucionario (PNR), fundado en 1929, argumentaron que la no reelección evitaría el continuismo y la formación de enclaves políticos dentro del Congreso federal, los gobiernos de los estados y las legislaturas locales.

Por ocho décadas México fue un caso atípico en el mundo de la política parlamentaria, el único además de Costa Rica, donde se prohibía que los legisladores pudieran reelegirse de manera consecutiva. ${ }^{1}$ Durante una visita a México hace años, el politólogo italiano Giovanni Sartori llamó a esa prohibición la extravagancia mexicana. En su opinión, la política legislativa en México "estaba de cabeza”, porque los legisladores, al no poderse reelegir, carecían de recompensas derivadas de su desempeño. Ninguna organización política puede funcionar eficazmente, concluía Sartori, si solo ofrece castigos pero ningún premio. Y en efecto, la proscripción que han enfrentado los legisladores mexicanos para desarrollar carreras parlamentarias atrofió el profesionalismo y la autonomía del Congreso, y lo debilitó frente al Poder Ejecutivo.

La reelección es un ingrediente central en la lógica de la política parlamentaria: una recompensa latente y visible que incentiva y moldea la conducta de los legisladores - quienes diseñan estrategias individuales para lograr visibilidad política, satisfacer a sus votantes y ser reelectos-. Su prohibición en México tuvo ingentes consecuencias sobre la conducta de los miembros del Congreso: al depender su futuro político no de sus electores - quienes no los podían reelegir - sino del partido y del presidente - quienes en el caso del PRI durante el siglo XX gozaban de los poderes de nominación y promoción política-, su desempeño estuvo vinculado para buscar el patrocinio y el patronazgo de "arriba" más que el apoyo de sus votantes. Con ello se trastocó la relación entre las ramas ejecutiva y legislativa de gobierno, motivando la supremacía de la primera sobre la segunda (Nacif, 1997b; Casar, 1999).

1 Artículo 107 de la Constitución de Costa Rica. Hasta 1996, la Constitución del Ecuador también prohibía la "reelección sucesiva" (artículo 57), pero una reforma quitó la restricción en ese año. 


\section{El fundamento constitucional: el artículo 59}

La institución de la no reelección consecutiva se refiere a la prohibición que existió entre 1933 y 2013 en el artículo 59 constitucional para que los legisladores se reeligieran para periodos consecutivos, aunque sí podían hacerlo después de un período intermedio.

Artículo 59. Los senadores y diputados al Congreso de la Unión no podrán ser reelectos para el período inmediato.

Los senadores y diputados suplentes podrán ser electos para el periodo inmediato con el carácter de propietarios, siempre que no hubieran estado en ejercicio; pero los senadores y diputados propietarios no podrán ser electos para el periodo inmediato con el carácter de suplentes.

\section{La reforma de 1933}

La cláusula de no reelección consecutiva fue establecida en 1933 como resultado de una propuesta del Partido Nacional Revolucionario (PNR), antecedente del PRI. La reforma buscaba prohibir la reelección en dos sentidos: en términos absolutos para presidente de la República y gobernadores de los estados, y solo de manera consecutiva para senadores, diputados federales, diputados locales y presidentes municipales, todos los cuales podrían ser reelegidos para el mismo cargo después de que hubiese transcurrido al menos un periodo intermedio. ${ }^{2}$ Uno de los principales

2 La reelección consecutiva había sido práctica común en México durante la mayor parte del siglo XIX y hasta 1933. Antes de ello, México había tenido un experimento que prohibía la reelección consecutiva entre 1814 y 1824, debido a que la Carta de Apatzingán de 1814 decía en su artículo 57 que "los diputados podrán ser reelegidos después de un período intermedio completo". Sin embargo, ulteriores Constituciones levantaron esa prohibición, haciendo posible la reelección consecutiva sin límites. Las constituciones de 1824, 1843, 1847, 1857 y 1917 no mencionan ninguna prohibición. Cuando la reforma de 1933 prohibió la reelección consecutiva, habían transcurrido más de cien años en que los legisladores, en todos los niveles y por todo el país, habían hecho sus carreras respondiendo a los incentivos creados por la institución de la reelección. Véase Béjar, Luisa, 1995, "La reelección parlamentaria en México", Asamblea 4:29-33, mayo.

En el caso de la presidencia de la República, desde la Constitución de 1824 y hasta la primera década del siglo XX, se había permitido la reelección en diversas modalidades. 
argumentos expuestos por los partidarios de la reforma antirreeleccionista fue que evitaría el continuismo y la formación de enclaves políticos dentro del Congreso federal, los gobiernos de los estados y las legislaturas locales. Para algunos de sus proponentes, la cláusula de no reelección intensificaría una sana circulación de élites al entrar en la vida política nacional toda una nueva generación de políticos jóvenes (Arnaut 1996).

Sin embargo, tras esas razones acaso la motivación más importante era consolidar el poder del PNR a escala nacional y en diversas regiones del país, lo cual implicaba reducir la influencia y poder de las legislaturas y de los gobiernos de los estados, así como de los ayuntamientos (Arnaut, 1996; Marván, 1997; Nacif, 1997a). Para Weldon:

Después de la Revolución, las legislaturas de los estados se volvieron el centro de la política local, el principal recurso de los partidos locales y de sus maquinarias... En estas circunstancias, podía haber buenos argumentos para prohibir la reelección de diputados locales si el objetivo era transferir poder del ámbito de la política local hacia el Comité Nacional del PNR (1994: 16).

Los líderes del partido pensaron que prohibiendo la reelección se ayudaría a ese propósito, ya que los caciques locales solían proteger su fuerza y sus recursos políticos apoyando y financiando la reelección de diputados locales afines a sus intereses. Bajo esa lógica, si la reelección era prohibida, los caciques perderían fuerza e influencia política al nivel local. ${ }^{3}$

La reforma antirreeleccionista fue aprobada por el Congreso, después de un intenso debate, durante los meses de noviembre y diciembre de

El 27 de noviembre de 1911, el presidente Francisco I. Madero aplicó una reforma que prohibía la reelección presidencial, y esa cláusula permaneció inalterada en la Constitución de 1917: en realidad, la cláusula de no reelección para el cargo de presidente fue una de las principales exigencias de Madero cuando la Revolución mexicana se hallaba en sus primeras etapas. Las cosas cambiaron con una reforma aplicada en 1927 que suprimía esa prohibición, permitiendo nuevamente la reelección, aunque sólo después de un periodo intermedio. Sin embargo, el asesinato de Alvaro Obregón motivó que la prohibición absoluta para la reelección presidencial se volviera a instaurar. Para una versión detallada, véase Careaga, Maite, 1996, Reformas institucionales que fracasan: el caso de la reforma reeleccionista en el Congreso mexicano, 1964-1965, pp. 32 y 33; González Oropeza, Manuel, 1994, "Comentario al artículo 83", Derechos del pueblo mexicano: México a través de sus Constituciones, t. IX, pp. 333-342.

3 Debe recordarse que el partido había sido fundado en 1929 por Plutarco Elías Calles, con objeto de dar estabilidad política y paz a un país que había sufrido guerras, golpes de estado, violencia y asesinatos políticos. Por ello era inaplazable sustituir el "caudillismo" - en palabras de Calles - por instituciones, y uno de los medios de combatir el "personalismo" en la política mexicana era reducir la influencia política de los caciques locales. 
1932, y la propuesta pasó, para su aprobación, a las legislaturas de los estados. El 29 de abril de 1933, la reforma que prohibía la reelección consecutiva fue promulgada y entró en vigor. ${ }^{4}$ Esta reforma institucional tendría efectos duraderos y considerables sobre la lógica y naturaleza de las relaciones entre el Ejecutivo y el Legislativo en México. Baste decir aquí que en el corto plazo, la reforma aumentó considerablemente la influencia política de Lázaro Cárdenas, quien en 1934 fue el primero de los candidatos presidenciales en intervenir en la conformación de listas de candidatos para el Congreso, con lo cual generó lealtades y se convirtió en el punto focal de promoción de carreras políticas en México.

En el mediano plazo, la no-reelección contribuyó a la concentración del poder en el ámbito nacional y, aunque no disminuyó automáticamente la fuerza de los caciques locales, gradualmente muchos de ellos usaron su influencia y dinero para apoyar el partido al nivel nacional, disminuyendo así su apoyo a los partidos y legislaturas locales. Según Nacif,

la fuente de los grandes poderes que la dirigencia nacional del PNR empezó a concentrar se hallaba... en su posición como coordinadora central de la circulación de los cuadros políticos en todos los puestos públicos de elección. Las reformas constitucionales de 1933 permitieron al PNR montar un sistema nacional de rotación de cargos que puso armas poderosas para premiar y castigar en manos del liderazgo del partido. Los políticos en sus cargos y fuera de ellos se volvieron completamente vulnerables y dependientes del mecanismo más extendido y eficaz de promoción política: el partido de la revolución (1997a: 124).

\section{El intento de contrarreforma de $1964^{5}$}

Pasaron 31 años para que el tema reeleccionista llegara nuevamente a los salones del Congreso. En 1964, la Cámara de Diputados aprobó una

4 Para una descripción detallada del proceso, véase Nacif, Benito, "La rotación de cargos legislativos y la evolución del sistema de partidos en México", Política y Gobierno, vol. IV, núm. 1, 1997, pp. 117-22, y Barquín Álvarez, Manuel, "Comentario al artículo 59”, Derechos del pueblo mexicano: México a través de sus Constituciones, 1994, pp. 271-284.

5 Para un relato detallado del intento hecho en 1964 por reinstalar la reelección consecutiva, véase Carega, 1996, y Careaga, n. d., "El fracaso de la reforma reeleccionista de 1964” (manuscrito). Para una perspectiva más vasta, véase Christlieb, Adolfo, Crónicas de la no-reelección, México, Ediciones de Acción Nacional, 1965, y Madrazo, Carlos, La tesis contra la reelección inmediata de los diputados y senadores del Congreso de la Unión, México, Partido Revolucionario Institucional, 1965. 
reforma para permitir nuevamente la reelección legislativa. La iniciativa provino del entonces Partido Popular Socialista (PPS), considerado entonces como un partido "satélite" del PRI. Sus promotores argumentaron que había llegado el momento de profesionalizar al Congreso y aumentar su responsabilidad política. Hubo críticos que dijeron que la reforma atentaba contra el "espíritu" de la Revolución mexicana estampado en el lema "Sufragio efectivo, no reelección”. Había confusión histórica y no se distinguía que el único clamor de Madero en 1910 fue en contra de la reelección presidencial, jamás de la legislativa.

Sin embargo, la reforma murió en el piso del Senado que desechó la iniciativa en septiembre de 1965. El bloqueador de aquel intento frustrado habría sido el presidente del PRI, Carlos A. Madrazo, quien aspiraba a ser candidato presidencial en 1970 y veía en la reelección riesgos para sus propias aspiraciones políticas. De acuerdo a algunas interpretaciones históricas, Madrazo tendría menos control e influencia sobre los legisladores si había reelección y, en cambio, uno de los potenciales contendientes, Alfonso Martínez Domínguez, coordinador de los diputados del PRI, se volvería poderoso y más viable como candidato.

Según Careaga, el entonces presidente Gustavo Díaz Ordaz apoyaba la reforma, e incluso llegó a convencer al líder parlamentario del PPS para que la presentara como suya. Ello le permitiría al presidente tener mayor campo de negociación con su propio partido. Si eso es cierto, parece extraño que el presidente, con toda la influencia que tenía sobre el partido, no hubiera podido garantizar la ratificación de la reforma por el Senado. Para Careaga, aunque Díaz Ordaz haya apoyado la reforma inicialmente, no estaba dispuesto a poner en riesgo su posición frente al partido por una reforma que aunque buscada, no era central en su programa político. Consecuentemente, tan pronto como el presidente se percató de la inesperada oposición a la reforma, aprovechó la contienda política entre grupos para fortalecer su posición como árbitro en la disputa. A causa de estas razones políticas, la reforma reeleccionista de 1964 pereció.

La reforma murió quizá por ambiciones políticas, y ni Madrazo ni Martínez fueron candidatos presidenciales. El primero moriría en un accidente aéreo un año después y el segundo ocuparía muchos cargos políticos en las décadas siguientes. Moriría en 2002. 


\section{El siglo XXI}

Pasaron otros 40 años para que el Congreso mexicano retomara nuevamente con seriedad la discusión del tema. A fines de 2004 el Senado aprobó en comisiones una reforma que abría la puerta a la reelección legislativa. El dictamen había sido firmado por 89 senadores de todos los partidos. Pero la iniciativa moriría en el pleno: cálculos políticos pesarían al interior del grupo parlamentario del PRI y el dictamen sería rechazado en febrero de 2005.

Una nueva esperanza renació en 2011 cuando el Senado aprobó una reforma política que proponía la reelección legislativa. Parecía que ahora sí era el momento histórico, el punto de inflexión para romper la causa central, aunque no única, de la impunidad y el bajo profesionalismo de los legisladores mexicanos. La iniciativa se presentó en abril y en noviembre del mismo año la reelección agonizaría nuevamente en el pleno, esta vez de los diputados. Con los votos del PRI, del Partido Verde y de Nueva Alianza, la propuesta de los senadores sería rechazada.

Fue hasta 2013 cuando en el contexto del Pacto por México y por iniciativa del Partido Acción Nacional, el tema entró en el paquete de negociación y fue incluido y votado a favor. En febrero de 2014 fue promulgado por el presidente de la República.

\section{La reforma constitucional de 2013}

A continuación se presentan seis de los principales argumentos esgrimidos a favor de la reelección durante las discusiones parlamentarias de la reforma constitucional de 2013, independientemente de que sus conclusiones se sostengan o no ante la evidencia de otros países:

a) Profesionaliza las carreras políticas. El prospecto de reelegirse y permanecer en el cargo por varios periodos consecutivos motiva a los legisladores y miembros de los ayuntamientos a informarse y aprender sobre diversas materias, a mejorar su técnica legislativa y a trabajar con mayor eficacia y disciplina.

b) Inyecta estabilidad política y legislativa. La presencia de legisladores, alcaldes, regidores y síndicos experimentados — que conciben la 
prudencia, la negociación y la discreción como herramientas básicas del quehacer político- estabiliza la relación Ejecutivo-Legislativo en el ámbito nacional y en los estados, a pesar de que las cámaras y ayuntamientos estén compuestos por una pluralidad de fuerzas políticas.

c) Fortalece el carácter representativo de la democracia. So pena de ser castigados en las urnas, los legisladores, alcaldes, regidores y síndicos prestan mayor atención a las preocupaciones de los electores de sus distritos y localidades, impulsando propuestas que atienden sus necesidades y defendiendo sus principales logros.

d) Incentiva la elaboración de proyectos de largo plazo. La reelección consecutiva incentiva la elaboración de proyectos que requieren de varios años para gestarse y registrar un impacto, reduciendo el riesgo de que queden truncos o sean percibidos como ineficaces.

e) Propicia una relación armónica entre funcionarios electos y cúpulas partidistas. La estabilidad que implica una relación de largo plazo permite la consolidación armónica de las relaciones de trabajo entre equipos indispensables para las labores legislativas, administrativas y políticas, fortaleciendo la confianza y la familiaridad en el trato.

f) Incrementa la eficacia. El horizonte más largo de los legisladores, alcaldes, regidores y síndicos facilita la discusión y resolución de asuntos políticos de gran trascendencia, cuyas negociaciones requieren de tiempo, conocimientos especializados, profesionalismo y mejor técnica legislativa.

Partiendo de estos argumentos y del hecho que la reelección no implica de manera automática que todos, o la gran mayoría de los legisladores y alcaldes, en efecto la conseguirán, se optó por modificar los artículos 59, 115 y 116 constitucionales de la siguiente manera: 


\section{Cuadro 1 \\ Modificaciones a artículos 59, 115 y 116 constitucionales en la reforma de 2013}

\begin{tabular}{|l|}
\hline \multicolumn{2}{|c|}{ Redacción antes de reforma } \\
\hline \multicolumn{2}{|c|}{ Artícu| } \\
\hline Los senadores y diputados al Congreso de \\
la Unión no podrán ser reelectos para el pe- \\
riodo inmediato. Los senadores y diputados \\
suplentes podrán ser electos para el periodo \\
inmediato con el carácter de propietarios, \\
siempre que no hubieren estado en ejercicio; \\
pero los senadores y diputados propietarios \\
no podrán ser electos para el periodo inme- \\
diato con el carácter de suplentes.
\end{tabular}

Artículo 115

I. Los presidentes municipales, regidores y síndicos de los ayuntamientos, electos popularmente por elección directa, no podrán ser reelectos para el periodo inmediato. Las personas que por elección indirecta, o por nombramiento o designación de alguna autoridad desempeñen las funciones propias de esos cargos, cualquiera que sea la denominación que se les dé, no podrán ser electas para el periodo inmediato. Todos los funcionarios antes mencionados, cuando tengan el carácter de propietarios, no podrán ser electos para el periodo inmediato con el carácter de suplentes, pero los que tengan el carácter de suplentes sí podrán ser electos para el periodo inmediato como propietarios a menos que hayan estado en ejercicio.
Los senadores podrán ser electos hasta por dos periodos consecutivos y los diputados al Congreso de la Unión hasta por cuatro periodos consecutivos. La postulación sólo podrá ser realizada por el mismo partido o por cualquiera de los partidos integrantes de la coalición que los hubieren postulado, salvo que hayan renunciado o perdido su militancia antes de la mitad de su mandato.
I. Las constituciones de los estados deberán establecer la elección consecutiva para el mismo cargo de presidentes municipales, regidores y síndicos, por un período adicional, siempre y cuando el periodo del mandato de los ayuntamientos no sea superior a tres años. La postulación sólo podrá ser realizada por el mismo partido o por cualquiera de los partidos integrantes de la coalición que lo hubieren postulado, salvo que hayan renunciado o perdido su militancia antes de la mitad de su mandato.
II. Los diputados a las legislaturas de los estados no podrán ser reelectos para el periodo inmediato. Los diputados suplentes podrán ser electos para el periodo inmediato con el carácter de propietario, siempre que no hubieren estado en ejercicio, pero los diputados propietarios no podrán ser electos para el periodo inmediato con el carácter de suplentes.

\section{Artículo 116}

II. Las constituciones estatales deberán establecer la elección consecutiva de los diputados a las legislaturas de los estados, hasta por cuatro periodos consecutivos. La postulación sólo podrá ser realizada por el mismo partido o por cualquiera de los partidos integrantes de la coalición que los hubieren postulado, salvo que hayan renunciado o perdido su militancia antes de la mitad de su mandato.

Fuente: elaboración propia. 
La nueva redacción de los artículos 59, 115 y 116 tiene al menos cuatro corolarios o implicaciones:

a) Impacta por igual a legisladores de distritos de mayoría relativa y a legisladores de circunscripciones plurinominales. Dado que simplemente se retiró la prohibición de la reelección inmediata, todos los legisladores podrán reelegirse por cualquiera de los dos mecanismos existentes (mayoría relativa o representación proporcional), abriendo la puerta para que legisladores que representan a un distrito de mayoría relativa busquen reelegirse por una circunscripción plurinominal y viceversa.

b) No pone en riesgo la unidad y disciplina de los grupos parlamentarios. $\mathrm{Al}$ dificultar que los legisladores se reelijan por un partido distinto al que los postuló en la elección anterior, la reforma no pone en riesgo la unidad y disciplina de los grupos parlamentarios, cuyos coordinadores tendrán la certeza de contar con un número estable de votos a lo largo de una legislatura. Los legisladores que quieran reelegirse por un partido distinto tendrán que renunciar durante los primeros 18 meses de su mandato al partido que los postuló, a su grupo parlamentario y a las comisiones en que participen (de lo contrario podrán ser removidos por sus coordinadores), lo que implica renunciar a beneficios económicos y políticos atractivos para cualquier aspirante a un cargo de elección popular.

c) No incentiva la disciplina partidista de alcaldes, regidores y síndicos. Aunque la reforma también obliga a los alcaldes, regidores y síndicos que quieran reelegirse por un partido distinto al que los postuló a renunciar a este partido durante los primeros 18 meses de su mandato, esta restricción no parece contribuir a la unidad y disciplina de los grupos de regidores, o a la lealtad partidista de los alcaldes, ya que no necesariamente implica una pérdida inmediata de beneficios económicos o políticos.

d) Deja en manos de los partidos las reglas para que sus legisladores, alcaldes, regidores y síndicos busquen la reelección. Al no referirse a los mecanismos de selección de candidatos al interior de los partidos, la reforma deja en manos de éstos las reglas para buscar la reelección, fortaleciendo su posición con relación a sus legisladores, alcaldes, regidores y síndicos. Salvo que las leyes secundarias estipulen, como en Argentina, que todos los partidos tienen la obligación de realizar elecciones primarias abiertas para elegir a sus candidatos, la última palabra sobre el mecanismo para seleccionar candidatos la seguirán teniendo los comités, las asambleas y los consejos de los partidos. 


\section{La reelección en perspectiva comparada}

Como parte de la reforma constitucional de 2013, el Congreso federal y los 32 congresos locales tendrán que reglamentar la reelección consecutiva de legisladores, alcaldes, regidores y síndicos en el transcurso de 2014. En este sentido, resulta útil echar un vistazo a América Latina, región que, además de ser el "vecindario" de México, se caracteriza por su similitud en aspectos relevantes como el sistema de gobierno (presidencial), el periodo de la última transición democrática (la llamada "tercera ola" de los años 80 y 90) y el nivel socioeconómico de sus habitantes (relativamente bajo con niveles altos de desigualdad).

La reelección por lo general se regula en tres aspectos. El primero es la "consecutiva", que se refiere a la posibilidad de que un ocupante del cargo compita para retenerlo en el siguiente periodo inmediato. De hecho, la "consecutividad" de la reelección es la restricción legal más común a esta figura en América Latina. El número de periodos que una persona puede reelegirse de manera consecutiva es la segunda restricción más importante y, aunque suele ser definida en función de la duración del cargo, lo más común en América Latina es que sea ilimitada. Un tercer conjunto de regulaciones relacionadas con la reelección son las referentes a la cohesión o disciplina de los grupos parlamentarios, definida como la distribución de incentivos al interior de un grupo para votar o no en bloque. Ahora bien, aunque el fin de estas regulaciones es preservar la cohesión o unidad de un grupo parlamentario - o la estabilidad de una mayoría a lo largo de una legislatura-, en la reforma constitucional mexicana de 2013 también se incluyeron como un mecanismo para garantizar que los partidos preserven el control de las candidaturas. En la medida en que los legisladores enfrenten más incentivos para permanecer en un grupo parlamentario, menor la probabilidad de que los dirigentes partidistas pierdan el control de la selección de candidatos.

Los cuadros 2, 3 y 4 describen, respectivamente, las principales modalidades de la reelección de diputados a los congresos nacionales, de senadores y de alcaldes en 18 países latinoamericanos. La codificación requirió de un análisis minucioso de las Constituciones, leyes y códigos electorales vigentes en febrero de 2014 en Argentina, Bolivia, Brasil, Chile, Colombia, Costa Rica, Ecuador, El Salvador, Guatemala, Honduras, México, Nicaragua, Panamá, Paraguay, Perú, República Dominicana, Uruguay y Venezuela. 
Cabe mencionar que, de los 18 países analizados, cuatro son Estados federales (Argentina, Brasil, México y Venezuela) y el resto son Estados unitarios. Mientras en los Estados unitarios las reglas para la reelección no varían a lo largo del territorio nacional, en los federales pueden variar en el ámbito tanto provincial como municipal. En este primer análisis se describen las legislaciones nacionales, señalando a los países con Estados federales donde la reelección de legisladores y alcaldes puede variar en el ámbito local. Posteriormente se describen las legislaciones locales en los cuatro países con Estados federales, resaltando los diferentes impactos del federalismo en las regulaciones.

\section{Reelección de diputados a los congresos nacionales}

De los 18 países analizados, nueve tienen congresos bicamerales y nueve unicamerales. La duración promedio del cargo de los diputados a los congresos nacionales es 4.2 años, con un mínimo de tres en El Salvador y México y un máximo de cinco en Bolivia, Nicaragua, Panamá, Paraguay, Perú, Uruguay y Venezuela.

Con respecto a la reelección consecutiva, Costa Rica figura como el único país que la impide, y con respecto al número de periodos consecutivos, Bolivia, Ecuador y México figuran como los únicos que fijan límites al número de periodos. Mientras en México el límite son cuatro periodos consecutivos equivalentes a 12 años en el cargo, en Bolivia y Ecuador es un periodo consecutivo equivalente a diez y ocho años, respectivamente. Por lo tanto, entre los países que fijan límites a los periodos consecutivos de los diputados, México es el que permite el mayor número de años en el cargo.

Por último, con respecto a la cohesión o unidad de los grupos parlamentarios, solo México y Panamá tienen provisiones legales, aunque de diferente índole. Mientras en Panamá los partidos tienen derecho a revocar el mandato de sus diputados por violaciones a sus estatutos, en México los diputados solo pueden buscar la reelección por el mismo partido o por cualquiera de los partidos integrantes de la coalición que los postuló, salvo que hayan renunciado o perdido su militancia en los primeros 18 meses de su mandato. 


\section{Cuadro 2}

\section{Modalidades de reelección de diputados en América Latina (Cámara única o baja)}

\begin{tabular}{|c|c|c|c|c|}
\hline País & $\begin{array}{c}\text { Tipo de } \\
\text { congreso }\end{array}$ & $\begin{array}{l}\text { Duración } \\
\text { del cargo }\end{array}$ & $\begin{array}{c}\text { Reelección } \\
\text { consecutiva }\end{array}$ & $\begin{array}{c}\text { Periodos } \\
\text { consecutivos }\end{array}$ \\
\hline Argentina* & Bicameral & 4 años & Sí & Ilimitado \\
\hline Bolivia & Bicameral & 5 años & Sí & Uno \\
\hline Brasil ${ }^{*}$ & Bicameral & 4 años & Sí & Ilimitado \\
\hline Chile & Bicameral & 4 años & Sí & Ilimitado \\
\hline Colombia & Bicameral & 4 años & Sí & Ilimitado \\
\hline Costa Rica & Unicameral & 4 años & No & -- \\
\hline Ecuador & Unicameral & 4 años & Sí & Uno \\
\hline El Salvador & Unicameral & 3 años & Sí & Ilimitado \\
\hline Guatemala & Unicameral & 4 años & Sí & Ilimitado \\
\hline Honduras & Unicameral & 4 años & Sí & Ilimitado \\
\hline México*** & Bicameral & 3 años & Sí & Tres \\
\hline Nicaragua & Unicameral & 5 años & Sí & Ilimitado \\
\hline Panamá ${ }^{\star *}$ & Unicameral & 5 años & Sí & Ilimitado \\
\hline Paraguay & Bicameral & 5 años & Sí & Ilimitado \\
\hline Perú & Unicameral & 5 años & Sí & Ilimitado \\
\hline $\begin{array}{c}\text { República } \\
\text { Dominicana }\end{array}$ & Bicameral & 4 años & Sí & Ilimitado \\
\hline Uruguay & Bicameral & 5 años & Sí & Ilimitado \\
\hline Venezuela* & Unicameral & 5 años & Sí & Ilimitado \\
\hline
\end{tabular}

* Estado federal.

** Contempla provisión legal en torno a cohesión o unidad de grupos parlamentarios.

Fuente: elaboración propia con leyes vigentes en febrero de 2014.

\section{Reelección de senadores}

La duración promedio del cargo de los senadores en los nueve países con cámara alta es 5.7 años, con un mínimo de cuatro en Colombia y República Dominicana y un máximo de ocho en Brasil y Chile. Cabe mencionar que en los nueve países se permite la reelección consecutiva, y que Bolivia y México son los únicos que limitan el número de periodos en el cargo. En ambos el límite es un periodo consecutivo, equivalente a un máximo de 12 años en México y de 10 en Bolivia. 
Por último, sólo México tiene una provisión legal en torno a la cohesión o unidad de los grupos de senadores. Esta provisión es idéntica a la prevista para los diputados. Por lo tanto, los senadores en México sólo pueden buscar la reelección por el mismo partido o por cualquiera de los partidos integrantes de la coalición que los postuló, salvo que hayan renunciado o perdido su militancia en los primeros tres años de su mandato.

\section{Cuadro 3}

Modalidades de reelección de senadores en América Latina

\begin{tabular}{|c|c|c|c|c|}
\hline País & $\begin{array}{c}\text { Tipo de } \\
\text { congreso }\end{array}$ & $\begin{array}{c}\text { Duración del } \\
\text { cargo }\end{array}$ & $\begin{array}{c}\text { Reelección } \\
\text { consecutiva }\end{array}$ & $\begin{array}{c}\text { Periodos } \\
\text { consecutivos }\end{array}$ \\
\hline Argentina* $^{*}$ & Bicameral & 6 años & Sí & Ilimitado \\
\hline Bolivia & Bicameral & 5 años & Sí & Uno \\
\hline Brasil $^{*}$ & Bicameral & 8 años & Sí & Ilimitado \\
\hline Chile & Bicameral & 8 años & Sí & Ilimitado \\
\hline Colombia & Bicameral & 4 años & Sí & Ilimitado \\
\hline México*** & Bicameral & 6 años & Sí & Uno \\
\hline Paraguay & Bicameral & 5 años & Sí & Ilimitado \\
\hline $\begin{array}{c}\text { República } \\
\text { Dominicana }\end{array}$ & Bicameral & 4 años & Sí & Ilimitado \\
\hline Uruguay & Bicameral & 5 años & Sí & Ilimitado \\
\hline
\end{tabular}

* Estado federal.

** Contempla provisión legal en torno a cohesión o unidad de grupos parlamentarios.

Fuente: elaboración propia con leyes vigentes en febrero de 2014.

\section{Reelección de alcaldes}

En 13 de los 18 países analizados, incluyendo a México, el municipio es la entidad administrativa de los alcaldes, al tiempo que en Panamá, Paraguay y Perú es el distrito, en Costa Rica es el cantón y en Chile es la comuna. Sin embargo, pese a la variación nominal, las atribuciones de los alcaldes son más o menos las mismas, teniendo como común denominador que el territorio que gobiernan es la división administrativa más pequeña con dirigentes representativos electos democráticamente.

La duración promedio del cargo de los alcaldes en estos países es 4.2 años - la misma que la de los diputados-, con un mínimo de tres en El Salvador y México y un máximo de cinco en Bolivia, Ecuador, Panamá, 
Paraguay y Uruguay. Llama la atención que la duración del cargo de los diputados y alcaldes sea la misma en todos los países salvo en Ecuador (cuatro vs. cinco años), Nicaragua (cinco vs. cuatro años), Perú (cinco vs. cuatro años) y Venezuela (cinco $v s$. cuatro años), acaso debido a que los ayuntamientos, integrados por alcaldes, concejales, regidores y síndicos, suelen realizar funciones legislativas sobre asuntos relacionados con el municipio.

Con respecto a la reelección consecutiva de alcaldes, se registran más restricciones que en la reelección de legisladores. Mientras solo Costa Rica impide la reelección consecutiva de legisladores, Colombia, Nicaragua y Paraguay impiden la reelección consecutiva de alcaldes.

Se observa una tendencia similar con respecto al número de periodos consecutivos de los alcaldes. Mientras diez países no fijan un límite al número de periodos, Bolivia, Brasil, Ecuador, México y Uruguay, solo permiten la reelección por un periodo consecutivo. Ahora bien, considerando la duración de los periodos de los alcaldes en estos países, México destaca como el que permite el menor número de años en el cargo (seis), al tiempo que en Brasil pueden permanecer hasta ocho y en Bolivia, Ecuador y Uruguay hasta diez.

Aunque las diferencias en la duración del cargo se deben a que concurren con la duración del cargo de los gobernadores (Bolivia, Brasil, Ecuador y México) e intendentes (Uruguay), México sobresale como el único donde la duración del cargo de alcalde no es la misma que la de gobernador. En México la reelección permitirá a un alcalde permanecer en el cargo durante el mismo tiempo que un gobernador, pero no más, como es el caso en Bolivia, Brasil, Ecuador y Uruguay. Es decir, ningún alcalde mexicano podrá permanecer en el cargo más tiempo que el gobernador de su entidad, situación que también se observa en Colombia, Nicaragua y Paraguay, los tres países que no permiten la reelección de alcaldes.

Cuadro 4

Modalidades de reelección de alcaldes en América Latina

\begin{tabular}{|c|c|c|c|c|}
\hline País & $\begin{array}{c}\text { Entidad } \\
\text { administrativa }\end{array}$ & $\begin{array}{c}\text { Duración del } \\
\text { cargo }\end{array}$ & $\begin{array}{c}\text { Reelección } \\
\text { consecutiva }\end{array}$ & $\begin{array}{c}\text { Periodos } \\
\text { consecutivos }\end{array}$ \\
\hline Argentina* $^{*}$ & Municipio & 4 años & Sí & $\begin{array}{c}\text { Varía por } \\
\text { provincia }\end{array}$ \\
\hline Bolivia $_{\text {Brasil }}^{*}$ & Municipio & 5 años & Sí & Uno \\
\hline Chile & Municipio & 4 años & Sí & Uno \\
\hline
\end{tabular}




\begin{tabular}{|c|c|c|c|c|}
\hline País & $\begin{array}{c}\text { Entidad } \\
\text { administrativa }\end{array}$ & $\begin{array}{c}\text { Duración del } \\
\text { cargo }\end{array}$ & $\begin{array}{c}\text { Reelección } \\
\text { consecutiva }\end{array}$ & $\begin{array}{c}\text { Periodos } \\
\text { consecutivos }\end{array}$ \\
\hline Colombia & Municipio & 4 años & No & NA \\
\hline Costa Rica & Cantón & 4 años & Sí & Ilimitado \\
\hline Ecuador & Municipio & 5 años & Sí & Uno \\
\hline El Salvador & Municipio & 3 años & Sí & Ilimitado \\
\hline Guatemala & Municipio & 4 años & Sí & Ilimitado \\
\hline Honduras & Municipio & 4 años & Sí & Ilimitado \\
\hline México*** & Municipio & 3 años & Sí & Uno \\
\hline Nicaragua & Municipio & 4 años & No & -- \\
\hline Panamá** & Distrito & 5 años & Sí & Ilimitado \\
\hline Paraguay & Distrito & 5 años & No & -- \\
\hline Perú & Distrito & 4 años & Sí & Ilimitado \\
\hline $\begin{array}{c}\text { República } \\
\text { Dominicana }\end{array}$ & Municipio & 4 años & Sí & Ilimitado \\
\hline Uruguay & Municipio & 5 años & Sí & Uno \\
\hline Venezuela* & Municipio & 4 años & Sí & Ilimitada \\
\hline
\end{tabular}

* Estado federal.

** Contempla provisión legal en torno a cohesión o unidad partidista.

Fuente: elaboración propia con leyes vigentes en febrero de 2014.

Ahora bien, de los cuatro países con Estados federales (Argentina, Brasil, México y Venezuela), Argentina es el único donde los límites a la reelección consecutiva varían entre provincias $-\mathrm{y}$ por ende entre municipios-. Mientras en Brasil, México y Venezuela el límite fijado en el ámbito nacional es el mismo en todas las provincias y municipios, en Argentina, ciudad de Salta no fija un límite al número de periodos que un alcalde puede permanecer en el cargo. Por ejemplo, la ciudad de Corrientes permite la reelección por un periodo único consecutivo al tiempo que en Argentina el límite de periodos consecutivos de los alcaldes lo determinan los congresos locales.

Por último, con respecto a la cohesión o unidad partidista, solo México tiene una provisión legal para los alcaldes, estipulando, como en el caso de los legisladores, que solo pueden buscar la reelección por el mismo partido o por cualquiera de los partidos integrantes de la coalición que los postuló, salvo que hayan renunciado o perdido su militancia en los primeros 18 meses de su mandato. 


\section{La reelección en el ámbito local de países federales}

De los 17 países analizados, Argentina, Brasil, México y Venezuela se distinguen por tener Estados federales. Sin embargo, entre éstos, Argentina destaca por ser el único donde las modalidades generales de reelección varían entre entidades federativas. El cuadro 5 describe las modalidades de reelección de legisladores locales en Brasil, México y Venezuela, donde no se registra variación entre entidades. El cuadro 6 describe las modalidades de reelección de legisladores locales en Argentina, donde sí se observa una variación importante en el ámbito estatal.

\section{Cuadro 5}

Modalidades de reelección de legisladores locales en Brasil, México y Venezuela (Cámara única o baja)

\begin{tabular}{|c|c|c|c|}
\hline País & Tipo de congresos & Duración del cargo & $\begin{array}{c}\text { Periodos consecutivos } \\
\text { de reelección }\end{array}$ \\
\hline $\begin{array}{c}\text { Brasil } \\
(27 \text { entidades })\end{array}$ & Unicamerales & 4 años & Indefinida \\
\hline $\begin{array}{c}\text { México } \\
(32 \text { entidades })\end{array}$ & Unicamerales & 3 años & Tres \\
\hline $\begin{array}{c}\text { Venezuela } \\
(25 \text { entidades })\end{array}$ & Unicamerales & 4 años & Indefinida \\
\hline
\end{tabular}

En el cuadro 5 sobresalen tres hallazgos. Primero, mientras en México el cargo de legislador local dura tres años, en Brasil y Venezuela dura cuatro. Segundo, mientras en México se fijó en tres el límite de periodos consecutivos, en Brasil y en Venezuela permanece indefinido. Por último, aunque los congresos locales de los tres países son unicamerales, México tiene el mayor número de entidades (32), seguido por Brasil (27) y Venezuela (25).

En el cuadro 6 también sobresalen cuatro hallazgos. Primero, de las 24 entidades argentinas, ocho tienen congresos bicamerales y 16 unicamerales. Segundo, con la excepción de Corrientes, en todas las entidades el cargo de legislador local - tanto de diputado como de senador-dura cuatro años. Tercero, sólo en cuatro de las 24 entidades - Ciudad de Buenos Aires, Neuquén, Tucumán y Santiago del Estero- se fija un límite al número de periodos consecutivos, pudiendo permanecer en el cargo un máximo de dos. Por último, de las ocho entidades con congresos bi- 
camerales, solo en Corrientes varía la duración del cargo entre cámaras: mientras el cargo de los diputados dura cuatro años, el cargo de los senadores dura seis.

\section{Cuadro 6}

Modalidades de reelección de legisladores locales en Argentina (Cámara única o baja)

\begin{tabular}{|c|c|c|c|}
\hline Entidad & Tipo de congreso & Duración del cargo & $\begin{array}{c}\text { Periodos consecutivos } \\
\text { de reelección }\end{array}$ \\
\hline $\begin{array}{c}\text { Ciudad de } \\
\text { Buenos Aires }\end{array}$ & Unicameral & 4 años & $\begin{array}{l}\text { Dos periodos } \\
\text { consecutivos }\end{array}$ \\
\hline Buenos Aires & Bicameral & $\begin{array}{l}4 \text { años ambas } \\
\text { cámaras }\end{array}$ & Indefinida \\
\hline Catamarca & Bicameral & $\begin{array}{l}4 \text { años ambas } \\
\text { cámaras }\end{array}$ & Indefinida \\
\hline Chaco & Unicameral & 4 años & Indefinida \\
\hline Corrientes & Bicameral & $\begin{array}{c}4 \text { años diputados y } 6 \\
\text { años senadores }\end{array}$ & Indefinida \\
\hline Formosa & Unicameral & 4 años & Indefinida \\
\hline Jujuy & Unicameral & 4 años & Indefinida \\
\hline La Pampa & Unicameral & 4 años & Indefinida \\
\hline Mendoza & Bicameral & $\begin{array}{c}4 \text { años ambas } \\
\text { cámaras }\end{array}$ & Indefinida \\
\hline Misiones & Unicameral & 4 años & Indefinida \\
\hline Neuquén & Unicameral & 4 años & $\begin{array}{l}\text { Dos periodos } \\
\text { consecutivos }\end{array}$ \\
\hline Tucumán & Unicameral & 4 años & $\begin{array}{l}\text { Dos periodos } \\
\text { consecutivos }\end{array}$ \\
\hline Tierra del Fuego & Unicameral & 4 años & Indefinida \\
\hline Córdoba & Unicameral & 4 años & Indefinida \\
\hline Rio Negro & Unicameral & 4 años & Indefinida \\
\hline San Juan & Unicameral & 4 años & Indefinida \\
\hline Santa Cruz & Unicameral & 4 años & Indefinida \\
\hline Santa Fe & Bicameral & $\begin{array}{c}4 \text { años ambas } \\
\text { cámaras }\end{array}$ & Indefinida \\
\hline $\begin{array}{l}\text { Santiago del } \\
\text { Estero }\end{array}$ & Unicameral & 4 años & $\begin{array}{l}\text { Dos periodos } \\
\text { consecutivos }\end{array}$ \\
\hline
\end{tabular}




\begin{tabular}{|c|c|c|c|}
\hline Entidad & Tipo de congreso & Duración del cargo & $\begin{array}{c}\text { Periodos consecutivos } \\
\text { de reelección }\end{array}$ \\
\hline Chubut & Unicameral & 4 años & Indefinida \\
\hline Entre Ríos & Bicameral & $\begin{array}{c}4 \text { años ambas } \\
\text { cámaras }\end{array}$ & Indefinida \\
\hline La Rioja & Unicameral & 4 años & Indefinida \\
\hline Salta & Bicameral & $\begin{array}{c}4 \text { años ambas } \\
\text { cámaras } \\
\text { años ambas } \\
\text { cámaras }\end{array}$ & Indefinida \\
\hline San Luis & Bicameral & \begin{tabular}{c}
4 Inda \\
\hline
\end{tabular}
\end{tabular}

Fuente: elaboración propia con leyes vigentes en marzo de 2014.

\section{Conclusiones}

La reforma electoral de 2013, al permitir la reelección consecutiva de legisladores, alcaldes, regidores y síndicos abre la puerta a la profesionalización de los funcionarios públicos, crea incentivos para mayor transparencia y devuelve a la ciudadanía un mecanismo fundamental para exigir cuentas a sus representantes. Sin embargo, el éxito de esta reforma depende de la manera en que se reglamente en los 32 congresos locales. En la medida que la reglamentación se limite a aspectos generales, es probable que se diluyan los efectos positivos de la reforma, permitiendo a los partidos retener el control de las candidaturas y relegando a la ciudadanía a un segundo plano en la toma de decisiones.

La reticencia de los partidos a ceder el control de las candidaturas se explica por los antecedentes históricos de la reelección en México, que se impidió desde 1933 para facilitar la renovación de cuadros y fomentar la competencia al interior de un partido que en aquel entonces aspiraba a dominar la vida política de México. En este sentido, la reelección representa una amenaza al control vertical que los partidos se han acostumbrado a ejercer en detrimento de la representación ciudadana. Por lo anterior, el principal reto de la reforma electoral de 2013 es transformar la palabra escrita en un mecanismo eficaz para mejorar la calidad de la democracia en México. 


\section{Bibliografía}

\section{Legislación por país}

Constitución Nacional de la Nación de Argentina, 2013, Buenos Aires, Argentina, Centro de documentación e información legislativa.

Código Nacional Electoral de Argentina, 2013, Buenos Aires, Argentina, Poder Judicial de la Nación y Cámara Nacional Electoral.

Constitución Política del Estado Plurinacional de Bolivia, 2009, La Paz, Bolivia, Tribunal Constitucional Plurinacional.

Ley del Régimen Electoral de Bolivia, 2011, La Paz, Bolivia, Tribunal Constitucional Plurinacional.

Constitución Brasileña, 2011, Brasilia, Brasil, Supremo Tribunal Federal. Código Electoral de Brasil, 2012, Brasilia, Brasil, Tribunal Supremo Electoral.

Constitución Política de la República de Chile, 2011, Santiago, Chile, Servicio Electoral de la República de Chile.

Ley Orgánica Constitucional sobre Votaciones Populares y Escrutinios (Ley 18.700), 2013, Santiago, Chile, Biblioteca del Congreso Nacional de Chile.

Constitución Política de Colombia, 2013, Bogotá, Colombia, Congreso de la República de Colombia.

Código Electoral de Colombia, 1986, Bogotá, Colombia, Consejo Nacional Electoral.

Constitución Política de Costa Rica, 2013, San José, Costa Rica, Asamblea Legislativa de la República de Costa Rica.

Código Electoral (Ley núm. 8765) de Costa Rica, 2009, San José, Costa Rica, Tribunal Supremo Electoral.

Constitución Política de la República de Ecuador, 2011, Quito, Ecuador, Ecuanex.

Ley Orgánica Electoral, Código de la Democracia de Ecuador, 2012, Quito, Ecuador, Consejo Nacional Electoral.

Constitución de la República de El Salvador, 2011, San Salvador, El Salvador, Asamblea Legislativa de la República de El Salvador.

Decreto Legislativo núm. 64 de El Salvador, 1991, San Salvador, El Salvador, Tribunal Supremo Electoral.

Constitución Política de la República de Guatemala, 2002, Guatemala, Guatemala, Tribunal Supremo Electoral. 
Ley Electoral y de Partidos Políticos de Guatemala, 1985, Guatemala, Guatemala, Tribunal Supremo Electoral.

Constitución de la República de Honduras, 2012, Tegucigalpa, Honduras, Tribunal Superior de Cuentas.

Ley Electoral y de las Organizaciones Políticas y sus Reformas de Honduras, 2009, Tegucigalpa, Honduras, Tribunal Supremo Electoral.

Constitución Política de los Estados Unidos Mexicanos, 2013, México, Tribunal Electoral del Poder Judicial de la Federación.

Código Federal de Instituciones y Procedimientos Electorales, 2008, México, Instituto Federal Electoral.

Constitución Política de Nicaragua, 2011, Managua, Nicaragua, Asamblea Nacional de Nicaragua.

Ley Electoral de Nicaragua, 2000, Managua, Nicaragua, Consejo Supremo Electoral.

Constitución Política de la República de Panamá, 2004, Panamá, Panamá, Asamblea Legislativa de la República de Panamá.

Código Electoral de Panamá, 2006, Panamá, Panamá, Tribunal Electoral. Constitución de la República del Paraguay. 2011, Asunción, Paraguay, Tribunal Supremo de Justicia Electoral.

Código Electoral de Paraguay. 1996, Asunción, Paraguay, Tribunal Supremo de Justicia Electoral.

Constitución Política del Perú, 2009, Lima, Perú, Tribunal Constitucional del Perú.

Ley Orgánica de Elecciones del Perú, 1997, Lima, Perú, Jurado Nacional de Elecciones.

Constitución de la República Dominicana, 2010, Santo Domingo, República Dominicana, Procuraduría General de la República.

Ley Electoral de la República Dominicana, 1997, Santo Domingo, República Dominicana, Junta Central Electoral.

Constitución de la República Oriental del Uruguay, 2004, Montevideo, Uruguay, Presidencia de la República Oriental del Uruguay.

Ley de Elecciones de Uruguay, 2000, Montevideo, Uruguay, Corte Electoral.

Constitución de la República Bolivariana de Venezuela, 2012, Caracas, Venezuela, Tribunal Supremo de Justicia.

Ley Orgánica del Poder Electoral de Venezuela, 2008, Caracas, Venezuela, Consejo Nacional Electoral. 